\title{
Evaluation of Copper Oxide-Based Interconnecting Materials
}

\author{
Yusuke Yasuda*, Eiichi Ide and Toshiaki Morita
}

Materials Research Laboratory, Hitachi, Ltd., 1-1 Omika-cho 7-Chome, Hitachi-shi, Ibaraki, 319-1292, Japan

\begin{abstract}
Copper (I) oxide $\left(\mathrm{Cu}_{2} \mathrm{O}\right)$ and copper (II) oxide $\left(\mathrm{Cu}_{2} \mathrm{O}_{2}\right)$ were investigated for their bondability as an interconnecting material. It was found that copper (II) oxide is more suitable than copper (I) oxide because the former is reduced at a lower temperature $\left(345^{\circ} \mathrm{C}\right)$ when molecular hydrogen is used as a reducing agent. A combined analysis of theoretically-calculated reduction paths, thermogravimetric/differential thermal analysis (TG-DTA) curves, and shear test results revealed that lower activation energy and higher stabilization energy for the reduction contribute to better mechanical and thermal properties of an interconnection.
\end{abstract}

Keywords: Interconnection, metal oxide, copper oxide, packaging, shear strength.

\section{INTRODUCTION}

There is an urgent demand for an interconnecting material with enhanced heat radiation and heat resistance performance. Such a material is expected to be used in the packaging of semiconductor power modules [1,2]. In these modules, semiconductor devices tend to be packed more densely and produce more heat per unit volume than those of previous generations. Also, the material is expected to be used for the packaging of an inverter near an engine in electric or hybrid vehicles. The inverter needs to have higher heat radiation and heat resistance performance to withstand an increased battery-current density and heat from the engine $[2,3]$. Needless to say, there is a demand for interconnecting materials which don't contain $\mathrm{Pb}$.

To satisfy the above demand, silver-based interconnecting materials have been developed [4-8]. A material using silver nanoparticles enables the formation of an interconnection at a lower temperature $\left(350^{\circ} \mathrm{C}\right.$ or lower) than traditional solders, while it still retains enhanced thermal properties [4-7]. However, the cost of synthesizing the nanoparticles is an obstacle that prevents this material being used in industry. As an alternative to silver nanoparticles, an interconnecting material using silver (I) oxide has been reported by Morita et al. [8]. They showed that during the process of interconnection formation, silver (I) oxide is first reduced with the help of myristyl alcohol around $140^{\circ} \mathrm{C}$, then silver nanoparticles are formed in situ. The in situ formation of nanoparticles contributes to better sintering properties, and results in superior thermal properties of the interconnection formed.

Since interconnections can be formed with silver (I) oxide, it is natural to consider the possibility of forming interconnections with copper oxide materials. Copper materials are superior to silver materials in terms of cost, while their expected heat radiation and heat resistance performance is similar to that of silver materials. In addition,

*Address correspondence to this author at the Materials Research Laboratory, Hitachi, Ltd., 1-1 Omika-cho 7-chome, Hitachi-shi, Ibaraki, 319-1292, Japan; Tel: 81-294-52-7574; Fax: 81-294-52-7634;

E-mail: yusuke.yasuda.jf@hitachi.com the resulting copper interconnections are expected to be more migration-resistant than silver interconnections.

There are two challenges in using copper oxides as interconnecting materials. The first challenge is to reduce the material efficiently. Because copper has much greater affinity to oxygen than silver does, the possible choice of a reducing agent that can reduce the copper oxide at $350^{\circ} \mathrm{C}$ or lower is limited. The faster the reduction, the less heat needs to be supplied. As the reduction proceeds, the reduced bare metal, which supposedly takes the form of nanoparticles, makes a bond. The mechanical strength of the bond increases as more oxides are reduced to bare metal. The second challenge is to minimize the volume change of the material upon reduction. A larger volume change would result in an increased void ratio in the interconnection. An increase in the void ratio is thought to cause inferior mechanical strength and heat radiation. Based on this view, copper (I) oxide (or cuprous oxide, $\mathrm{Cu}_{2} \mathrm{O}$ ) is preferable to copper (II) oxide (or cupric oxide, $\mathrm{CuO}$ ) due to the lower oxygen content in the chemical composition.

The reduction of copper oxides has been studied prior to this work [9-12]. Rodriguez et al. shows that the reduction of copper (II) oxide occurs by a direct transformation mechanism instead of by sequential transformation using an in situ time-resolved X-ray diffraction technique [9]. Kim et al. compare the reduction of copper (I) and copper (II) oxides with hydrogen molecules and showed that the activation energy for the reduction of copper (II) oxide is about $60.7 \mathrm{~kJ} / \mathrm{mol}$ while the value is $114.6 \mathrm{KJ} / \mathrm{mol}$ for copper (I) oxide [1]. Two research groups showed that copper (II) oxide is easier to be reduced than copper (I) oxide with reducing agents other than hydrogen molecules $[11,12]$.

Summarizing the above considerations, copper (I) oxide is preferable in terms of minimizing the volume change, but copper (II) oxide is better in terms of reducibility. As a consequence, it is difficult to predict which oxide is better suited as an interconnecting material. Thus, both copper (I) and copper (II) oxides as well as silver (I) oxide as a reference were investigated. In interconnection formation experiments using hydrogen molecules as a reducing agent, it was revealed that copper (II) oxide is more suitable for 
forming interconnections. Theoretical calculations were shown to be useful in interpreting and complementing the experimental results. Bond strengths of the resulting interconnections using copper (II) oxide were weaker than those formed with silver (I) oxide. However, it may be possible to improve the mechanical strength by choosing a different reducing agent. Therefore, we conclude that copper (II) oxide is a candidate material for future interconnections.

\section{METHODS AND MATERIALS}

\subsection{Theoretical Calculation and Materials}

Three metal oxides, copper (I) oxide, copper (II) oxide, and silver (I) oxide were modeled by $\mathrm{Cu}_{2} \mathrm{O}, \mathrm{Cu}_{2} \mathrm{O}_{2}$, and $\mathrm{Ag}_{2} \mathrm{O}$ clusters, respectively. These clusters, shown in Fig. (1), model a local structure of a metal oxide surface. (a)

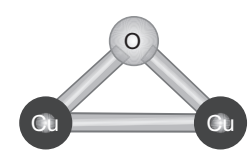

(b)

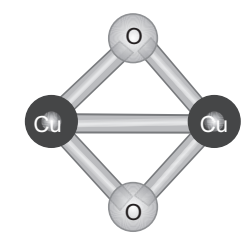

(c)

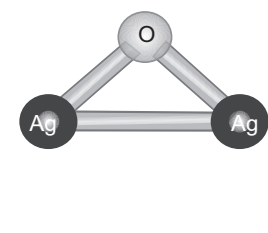

Fig. (1). Cluster-model structures of (a) copper (I) oxide, (b) copper (II) oxide, and (c) silver (I) oxide.

Oxygen reductions of the metal oxides by a hydrogen molecule were investigated. Assumed reactions for copper (I) oxide, copper (II) oxide and silver (I) oxide were as follows.

$$
\begin{aligned}
& \mathrm{Cu}_{2} \mathrm{O}+\mathrm{H}_{2} \rightarrow 2 \mathrm{Cu}+\mathrm{H}_{2} \mathrm{O} \\
& \mathrm{Cu}_{2} \mathrm{O}_{2}+\mathrm{H}_{2} \rightarrow \mathrm{Cu}_{2} \mathrm{O}+\mathrm{H}_{2} \mathrm{O} \\
& \mathrm{Ag}_{2} \mathrm{O}+\mathrm{H}_{2} \rightarrow 2 \mathrm{Ag}+\mathrm{H}_{2} \mathrm{O}
\end{aligned}
$$

To determine the reaction path for each of the above reactions, global minimum structures of the reactant and product were first investigated. Since both the reactant and product were made of two molecules, the structure of each molecule was first optimized. Then, mutual positions and orientations of these two molecules giving the lowest energy were searched for by optimizing all variables describing two molecules as a whole. Obtained reactant and product structures were verified to be at the bottom of the potential energy surface; these structures had no imaginary vibrational frequencies. Transition state structures were searched for starting from an initial-guess structure generated by using both the lowest-energy reactant and product structures [13]. Obtained transition state structures were verified to have only one imaginary frequency that corresponded to the reactant-to-product transition path.

From the obtained structures and their Gibbs free energies, $G$, at $27^{\circ} \mathrm{C}$ and $0.101325 \mathrm{MPa}$, activation energy $E^{\dagger}$ and stabilization energy $E_{\text {stab }}$ were calculated. These energy quantities were defined as follows.

$E^{\dagger}=G($ transition structure $)-G($ reactant $)(4)$

$E_{\text {stab }}=G($ reactant $)-G($ product $)(5)$

Calculations were performed using density functional theory. A combination of Becke's exchange functional and Perdew and Wang's correlation functional (BPW91) was used for describing exchange and correlation interactions $[14,15]$. A LANL2DZ basis set with the relativistic effective inner-core potential and split-valence type valence basis set functions [16] was used for copper and silver atoms, and a $6-31+G(d, p)$ basis set [17] was used for hydrogen and oxygen atoms. Among the tested combinations of functionals and basis sets, the combination of the BPW91 functional and LANL2DZ basis set was reported to most accurately reproduce molecular geometries, vibrational frequencies, and dissociation energies for gold-, silver-, and coppercontaining molecules [18]. Since the investigated reactions involved hydrogen molecule to water transition, an allelectron basis set containing polarization and diffuse functions was used for a better description of hydrogen and oxygen atoms. All the calculations were performed using the Gaussian03 program [19].

Powdery samples of copper (I) oxide (Kanto Chemical Co., Inc.), copper (II) oxide (Wako Pure Chemical Industries, Ltd.), and silver (I) oxide (Wako Pure Chemical Industries, Ltd.) were purchased and used as received. Particle sizes of the powdery samples were 1 to $3 \mu \mathrm{m}$ in diameter, as shown in Fig. (2).

\subsection{Experiment}

Thermogravimetric/differential thermal analysis (TGDTA) was performed with a TGA/SDTA851 (MettlerToledo) analyzer on each of the metal oxides. All measurements were done in $3 \% \mathrm{H}_{2}$ and $97 \% \mathrm{~N}_{2}$ gas mixture of atmospheric pressure with a flow rate of $80 \mathrm{~cm}^{3} / \mathrm{min}$. The heating rate was set to $10^{\circ} \mathrm{C} / \mathrm{min}$. The amounts of metal oxides used were $11.32 \pm 0.10 \mathrm{mg}$.

A pair of specimens of copper, illustrated in Fig. (3a), was prepared for a shear test (JIS Z3198-5). One specimen was $10 \mathrm{~mm}$ in diameter and $5 \mathrm{~mm}$ thick. The other specimen was $5 \mathrm{~mm}$ in diameter and $2 \mathrm{~mm}$ thick. A powdery metal oxide was applied on the larger specimen surface with metal mask (6 $\mathrm{mm}$ in diameter; $50 \mu \mathrm{m}$ thick). Then the smaller specimen was put on top of the applied region.

The pair of specimens was placed in a vacuum reflow system (Shinko Seiki) of $\mathrm{H}_{2}$ ambience heated at $350^{\circ} \mathrm{C}$. In the furnace, the specimens were pressurized from opposite directions at $1.2 \mathrm{MPa}$ for 5 minutes to form an interconnection between the specimens, as shown in Fig. (3b).

The shear strength of one joint obtained by each metaloxide particle was measured with a bond tester SS-100KP (Seishin Trading) to evaluate the bond strength. The speed of the sheer arm, illustrated in Fig. (3c), was set to $30 \mathrm{~mm} / \mathrm{min}$. Load was applied to the smaller specimen until the interconnection fractures. The shear strength was calculated as the maximum load at the time of the fracture divided by the area of the smaller specimen surface.

A cross section of the bonded layer was observed with a Hitachi S-4200 scanning electron microscope (SEM) at an accelerating voltage of $5 \mathrm{kV}$. The cross-sectional samples finished by buffing them with diamond paste (particle diameter: $0.25 \mu \mathrm{m}$ ) using a special polishing oil, followed by a Flat Milling Device E-3200 (Hitachi) for $180 \mathrm{~s}$ (at an accelerating voltage of $15 \mathrm{kV}$ ). 
(a)

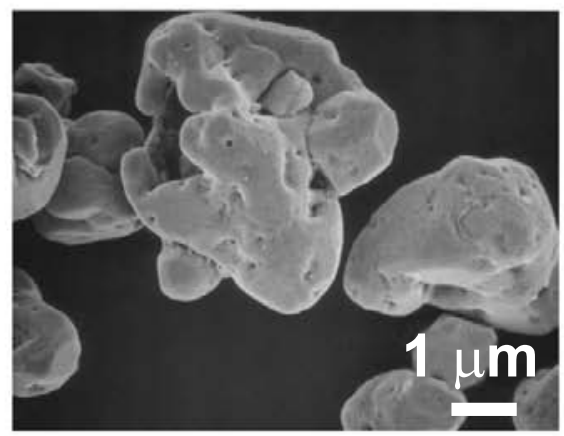

(b)

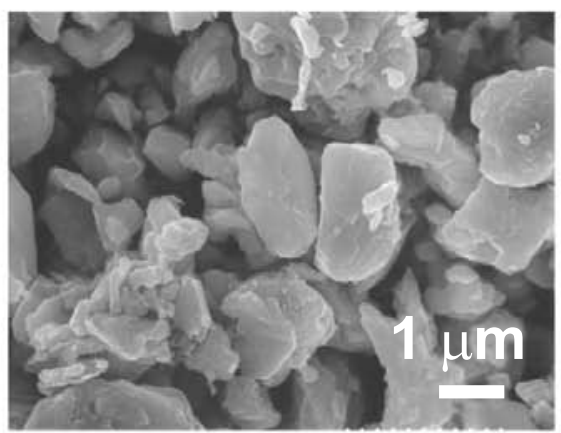

(c)

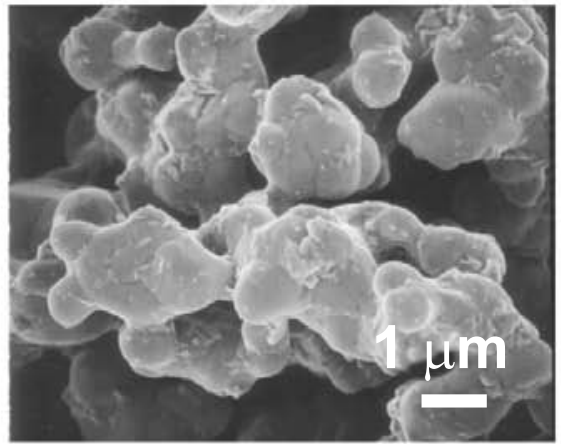

Fig. (2). Appearance of powdery samples used in this study. (a) Copper (I) oxide, (b) copper (II) oxide, and (c) silver (I) oxide.

$\mathrm{X}$-ray diffraction (XRD) patterns for fracture surface of the layer formed by using copper (II) oxide and silver (I) oxide for bonding at $350{ }^{\circ} \mathrm{C}$ were acquired by diffractometer (model RU200B, Rigaku Corporation). XRD data were collected at room temperature by using monochromatized $\mathrm{Cu}$-K $\alpha \mathrm{X}$-rays $(\lambda=1.5418 \AA$ ) .

\section{RESULTS}

\subsection{Calculated Reaction Path}

Fig. (4) shows calculated structures of reactants, transition states, and products in metal oxide reduction by a hydrogen molecule. Common to all the investigated metal oxides, hydrogen molecules stay near an oxygen atom in the reactant structure. Then, a hydrogen atom binds to the oxygen atom in the transition states. Finally, the hydrogen and oxygen atoms reorder to form a water molecule in the product structures. The water molecules reorient and stay near a metal atom. Reaction mechanisms for copper (I) oxide (Fig. 4a) and silver (I) oxide (Fig. 4c) are the same. In the figure, $d_{\mathrm{mm}}$ and $d_{\mathrm{mo}}$ represent the metal-metal and metaloxygen atomic distance, respectively. Values of $d_{m m}$ and $d_{m o}$ will be discussed later.

Table 1 lists calculated values of stabilization energy $E_{\text {stab }}$ and activation energy $E^{\dagger}$ for the metal oxide reduction by a hydrogen molecule. The values of $E^{\dagger}$ decreased in the order of copper (I) oxide, copper (II) oxide, and silver (I) oxide, while those of $E_{\text {stab }}$ increased in this order. This result indicated that the oxygen reduction could proceed by chainreaction because the stabilization energy produced at one place can be used to overcome the activation energy of reduction in another place. Calculated values of $E^{\dagger}$ for copper (I) and copper (II) oxides were in good agreement with experimentally determined values [10]. The value for copper (I) oxide was about two times larger than that for copper (II) oxide or silver (I) oxide. The value of $E^{\dagger}$ for silver (I) oxide was $15.1 \mathrm{KJ} / \mathrm{mol}$ less than that for copper (II) oxide.

\subsection{TG-DTA}

Fig. (5) shows TG-DTA curves of copper (I) oxide, copper (II) oxide, and silver (I) oxide in a $3 \% \mathrm{H}_{2}$ and $97 \%$ $\mathrm{N}_{2}$ gas mixture. The values of TG represent the weight loss/gain of the oxides. For all the oxides, the TG value decreased upon heating due to the loss of oxygen by reduction and became constant at a specific temperature. The total percentage of the weight loss was larger in copper (II) oxide (Fig. (5b) than in the other two due to the higher oxygen content in its chemical composition. The temperature at which a TG value became constant can easily be distinguished from the visual inspection of the figure and is labeled $T(100 \%)$, meaning the temperature at which $100 \%$ of the total weight loss occurred. It is more difficult to see at which temperature the reduction started. As an index related to the latter temperature, the temperature where $10 \%$ of weight loss occurred was defined and labeled $T(10 \%)$ in the figure. Additionally, the difference between these two temperatures was defined as $\Delta T=T(100 \%)-T(10 \%)$. A value of $\Delta T$ divided by 10 gives the reaction time in minutes because the temperature was increased at a constant rate $\left(10^{\circ} \mathrm{C} / \mathrm{min}\right)$ in this measurement. The values of $T(10 \%)$, $T(100 \%)$, and $\Delta T$ are given in Table 2 . The values of DTA in Fig. (5) represent heat that was released. Just below $T(100 \%)$ the DTA values reached a maximum. The DTA peak became higher in the order of copper (I) oxide (Fig. 5a), copper (II) oxide (Fig. 5b), and silver (I) oxide (Fig. 5c).

Note that when identifying the effective starting point of a reaction, a measure like $T(10 \%)$ is used in other fields. For 
(a)

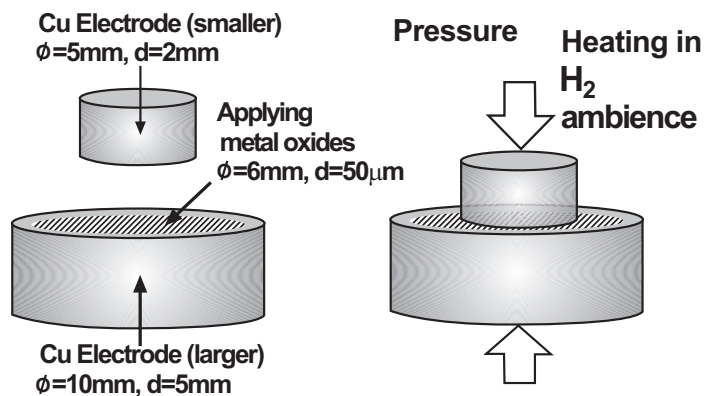

(c)

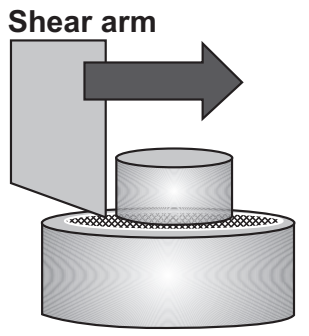

Fig. (3). Processes of the interconnect formation and bond strength evaluation. (a) Definition of the specimens used in a shear test (JISZ3198-5); ø: diameter, d: thickness. (b) Interconnection formation. (c) Shear strength measurement.

example, in medicinal chemistry, the concentration of medicine molecules that block $10 \%$ of the activity of a target protein is used as an index called IC10 [20-22].

\subsection{Bond Characteristic}

Fig. (6) shows the result of bond strength evaluation using copper (I), copper (II), or silver (I) oxides as an interconnecting material. The bond strength for Copper (I)

\section{Reactant Transition State Product}

(a)
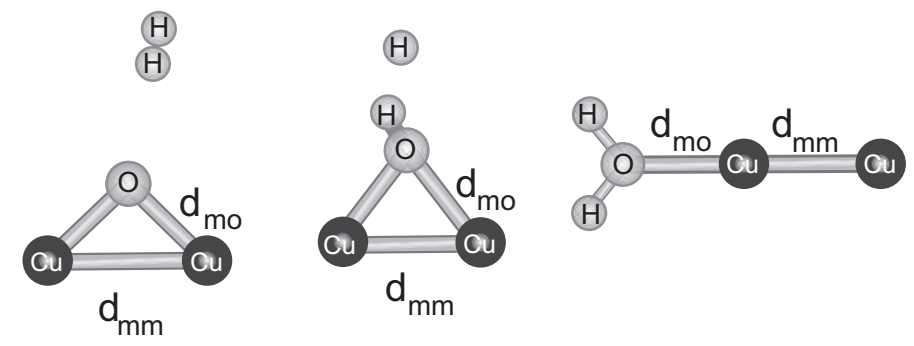

(b)
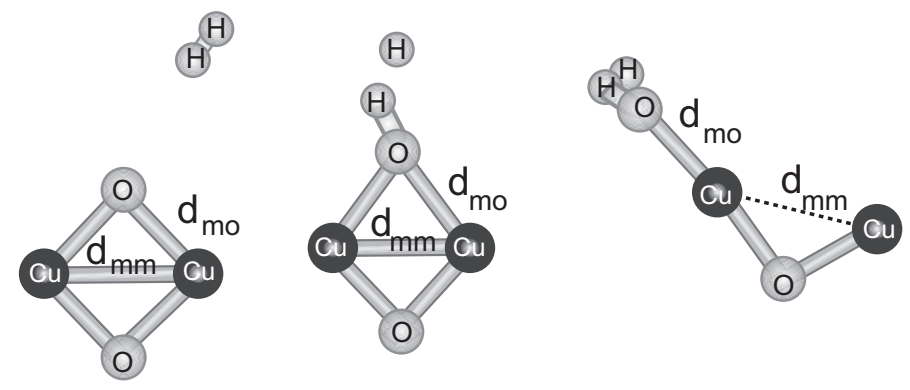

(c)
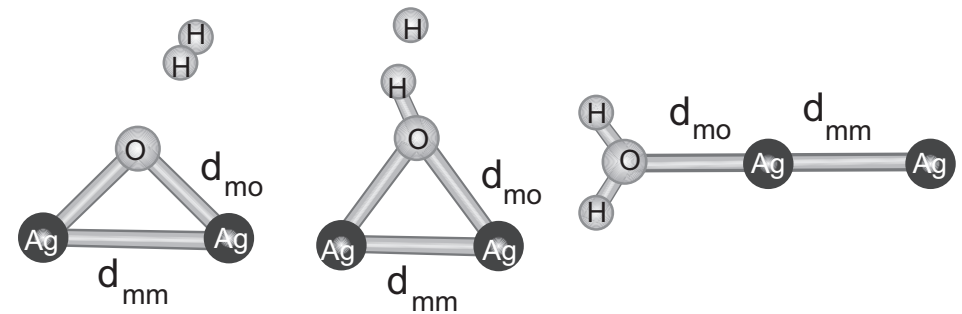

Fig. (4). Calculated structures of reactants, transition states, and products in (a) copper (I) oxide, (b) copper (II) oxide, and (c) silver (I) oxide reduction by hydrogen molecule. Symbols $d_{\mathrm{mm}}$ and $d_{\mathrm{mo}}$ represent metal-metal atomic distance and metal-oxygen atomic distance. 
oxide was $1 \mathrm{MPa}$ or lower, while the value for Copper (II) oxide was $17 \mathrm{MPa}$ at $350{ }^{\circ} \mathrm{C}$. Also, the bond strength for silver (I) was $23 \mathrm{MPa}$.

Table 1. Calculated Values of Activation Energies $E^{\dagger}$ and Stabilization Energies $E_{\text {stab }}$ for Different Metal Oxide Reduction Reactions by Hydrogen Molecule $(\mathrm{KJ} / \mathbf{m o l})$

\begin{tabular}{|c|c|c|}
\hline Metal Oxide & $\boldsymbol{E}^{\dagger}$ & $\boldsymbol{E}_{\text {stab }}$ \\
\hline \hline copper (I) oxide & $119.7(114.6)^{*}$ & 155.2 \\
\hline copper (II) oxide & $68.2(60.7)^{*}$ & 245.6 \\
\hline silver (I) oxide & 53.1 & 275.7 \\
\hline Experimental values [10].
\end{tabular}

(a)

(b)

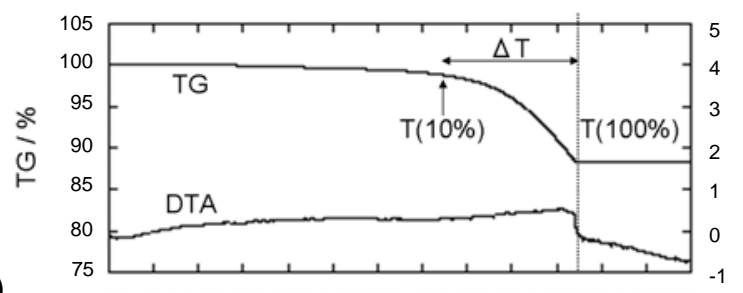

(c)
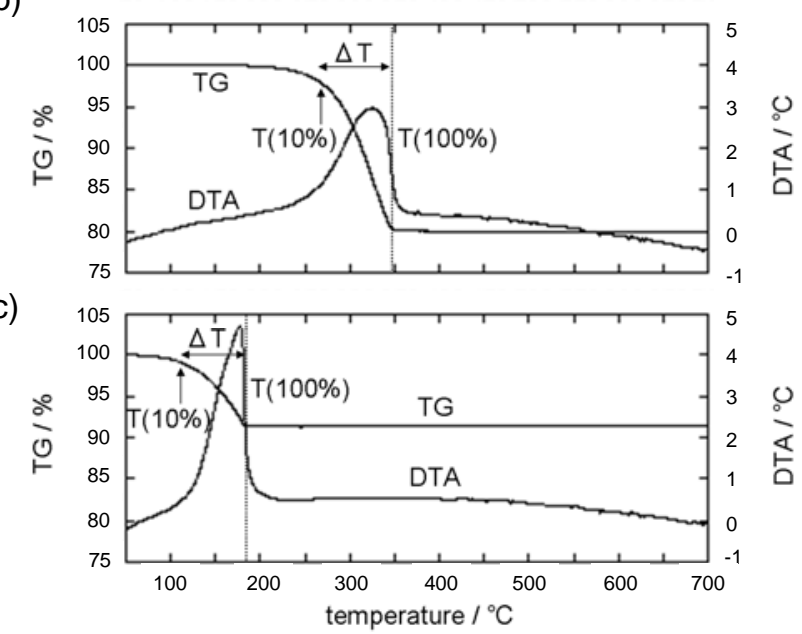

Fig. (5). TG-DTA curves of (a) copper (I) oxide, (b) copper (II) oxide, and (c) silver (I) oxide.

Table 2. Values of $T(10 \%), T(100 \%)$, and $\Delta T$ Defined in Fig. (5) $\left({ }^{\circ} \mathrm{C}\right)$

\begin{tabular}{|c|c|c|c|}
\hline Metal Oxide & $\mathbf{T}(\mathbf{1 0 \%})$ & $\mathbf{T}(\mathbf{1 0 0 \%})$ & $\boldsymbol{\Delta T}$ \\
\hline \hline copper (I) oxide & 422 & 572 & 150 \\
\hline copper (II) oxide & 265 & 345 & 80 \\
\hline silver (I) oxide & 110 & 180 & 70 \\
\hline
\end{tabular}

\section{DISCUSSION}

4.1. Relationship Among the Calculated Reaction Path, the TG-DTA Result, and the Bond Strengths

The measured thermophysical profile by TG-DTA can be explained by using the calculated energy quantities. Fig. (7) shows two correlation plots between the measured and calculated quantities. Fig. (7a) is a $T(10 \%)$ versus $E^{\dagger}$ plot for the reduction of the three metal oxides. Since $T(10 \%)$ is an index related to the temperature at which the reduction reaction starts, values of $T(10 \%)$ highly correlate with activation energy $E^{\dagger}$ with $R^{2}=0.91 \quad(R$ : correlation coefficient). Fig. (7b) is a $\Delta T$ versus $E_{\text {stab }}$ plot for the reduction reaction of the three metal oxides. The quantity $\Delta T$ is related to the reaction time. A high correlation of $R^{2}=0.98$ indicates the following reaction process; the larger the $E_{\text {stab}}$, the more heat is produced at a reaction site after the reduction is completed. The produced heat is used to induce a subsequent reduction in the vicinity of where the previous occurred. This process continues as a chain reaction until there are no oxides left. Therefore, a reaction with a higher $E_{\text {stab }}$ terminates in a shorter time.

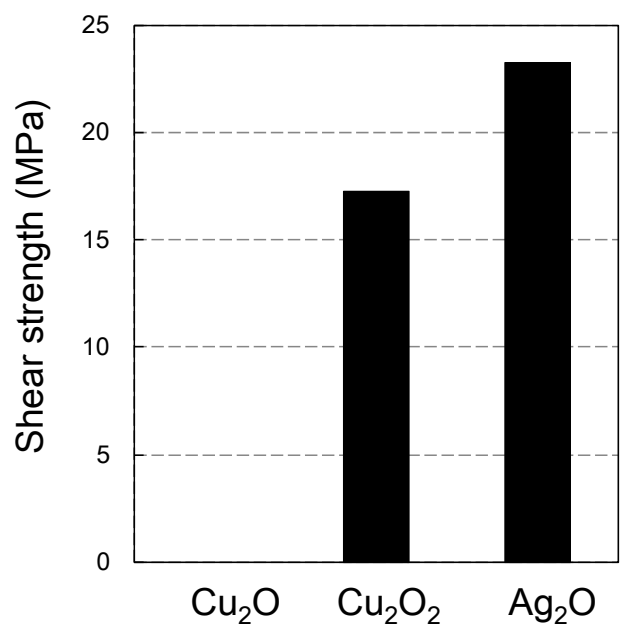

Fig. (6). Bond strength (MPa) using copper (I) oxide, copper (II) oxide, or silver (I) oxide.

It is straightforward to relate the TG-DTA measured quantities and the obtained bond strength. Remember that the interconnections were formed under the conditions of a $350^{\circ} \mathrm{C}$ bonding temperature for 5 minutes. At this temperature, no copper (I) oxide is expected to be reduced as inferred from the TG-DTA measurement. Therefore, the bond strength was $1 \mathrm{MPa}$ or lower. On the other hand, the strength of copper (II) oxide and silver (I) oxide were 17 and $23 \mathrm{MPa}$, respectively. Figs. $(\mathbf{8}, \mathbf{9})$ show cross section of bond layers for copper (II) oxide and silver (I) oxide observed by SEM. In the figures, the sintering of the metal particles was observed, respectively. The metal particle was produced by the reduction of metal oxide particles (copper (II) oxide and silver (I) oxide), which was confirmed by the TG/DTA and XRD measurements. The reduction temperature for copper (II) oxide and silver (I) oxide were $345{ }^{\circ} \mathrm{C}$ and $180{ }^{\circ} \mathrm{C}$, respectively as shown in Table $\mathbf{2}$. Fig. (10a, b) shows the XRD measurements of the fracture surface of the layer formed by using copper (II) oxide and silver (I) oxide for bonding at $350{ }^{\circ} \mathrm{C}$. In the Fig. (10a), the pattern showed peaks at 43.3, 50.3 and 74.2 degree attributed to those of copper (JCPDS card No. 4-0836) was observed, and in the Fig. (10b), peaks at 38.1, 44.3, 64.4 and 74.4 degree attributed to those of silver (JCPDS card No. 4-0783) was observed (peaks at 43.3, 50.3 and 74.2 degree are due to the copper disk used for the shear strength measurement). Accordingly, no metal-oxides peak was observed in the 
XRD patterns. These considerations indicated that the higher bond strength was achieved by the sintering of the metal particles from metal oxide particles. Also, although the in situ formation of nanoparticle for the copper (II) oxide and silver (I) oxide in the reduction was not confirmed in this study, the nanoparticles would be formed in the reduction during the bonding, as is the case with the use of myristyl alcohol for silver (I) oxide reduction [8], and contribute to the low temperature sintering and bond to the copper electrode.

(a)

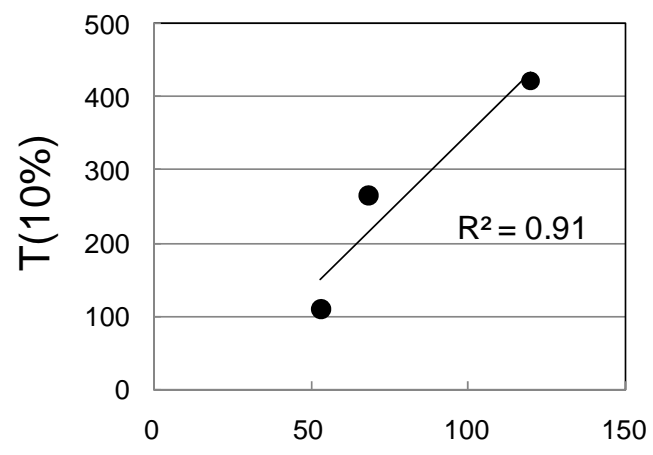

$\mathrm{E}^{\dagger} / \mathrm{KJ} / \mathrm{mol}$

(b)

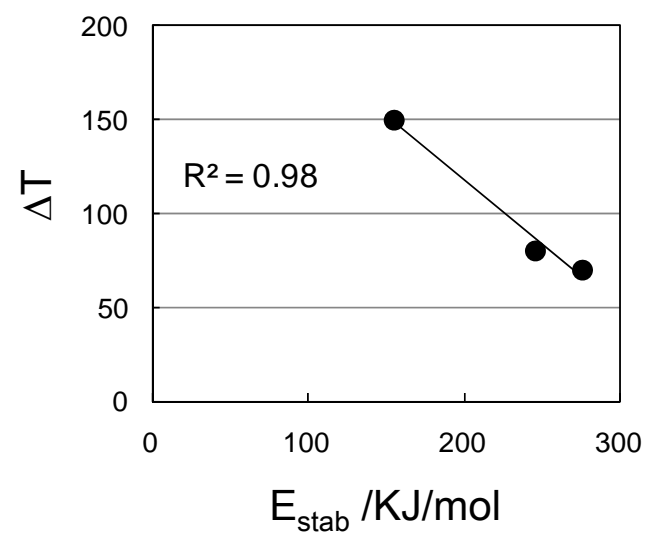

Fig. (7). Correlation plots between measured and calculated quantities. (a) $T(10 \%)-E^{\dagger}$ plot for the reduction reaction of the three metal oxides. (b) $\Delta T-E_{\text {stab }}$ plot for the reduction reaction of the three metal oxides. See text for the definitions of physical quantities.

\subsection{Relationship Between Calculated Reaction Path and Bond Strength}

Fig. (11) plots values of $d_{\mathrm{mm}}$ and $d_{\text {mo }}$ of the reactant, transition state, and product structures for the three metal oxide reductions. The values for copper (I) oxide and silver (I) oxide show a similar behavior; both $d_{\mathrm{mm}}$ and $d_{\text {mo }}$ values decrease as the reaction proceeds. The difference between these two is simply explained as the difference in bond lengths; the elongation of a shorter bond requires more energy, as in the copper (I) oxide case. The values of $d_{\mathrm{mm}}$ (a)

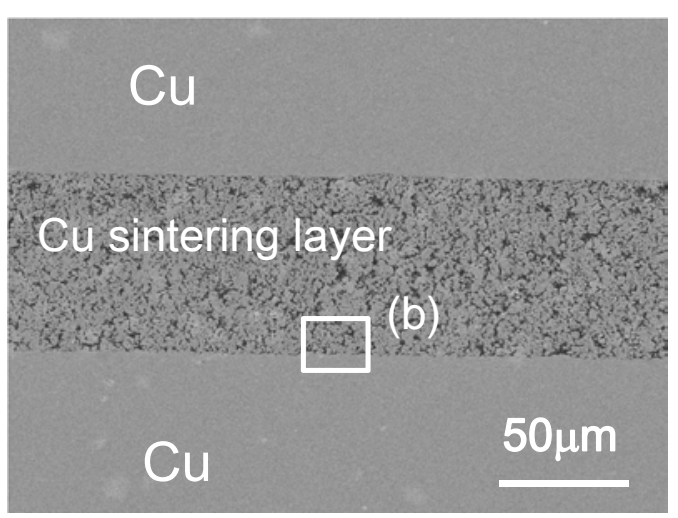

(b)

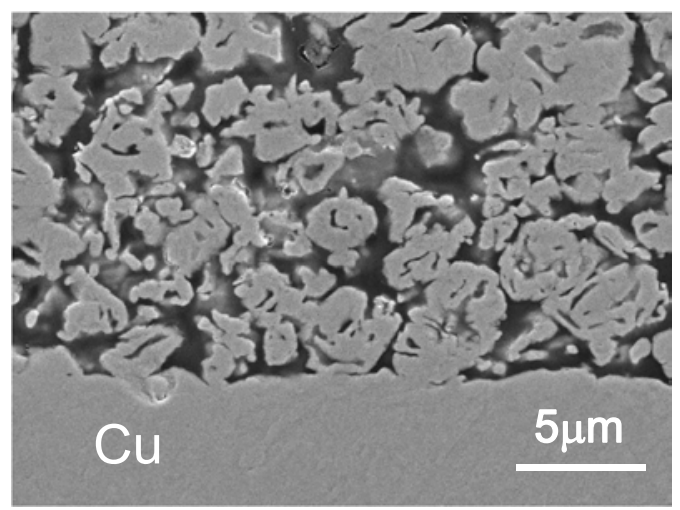

Fig. (8). Cross-sectional SEM imaged of copper (II). (a) lowmagnification image and (b) high magnification image of marked area in (a).

and $d_{\text {mo }}$ for copper (II) oxide show different behavior from those for the other two oxides. The values of $d_{\mathrm{mm}}$ hardly change when going from the reactant to the transition state. The change in the values of $d_{\mathrm{mo}}$ is smaller than that for copper (I) oxide. These two structural factors seem to contribute to lower activation energy in copper (II) oxide than in copper (I) oxide. In previous studies, it was shown that copper (II) oxide was reduced directly to copper $[9,10]$. On the other hand, $\mathrm{Cu}_{2} \mathrm{O}_{2}$ to $\mathrm{Cu}_{2} \mathrm{O}$ reduction is assumed to be the first elementary reaction in the reduction in our calculation. Theoretical modeling and calculation of the direct reduction reaction will be addressed in the future.

\section{CONCLUSIONS}

Copper (I) oxide and copper (II) oxide were investigated for their suitability as an interconnect material. We found that copper (II) oxide was more suitable for the interconnection than copper (I) oxide because the former was reduced at a lower temperature $\left(345^{\circ} \mathrm{C}\right)$ when molecular hydrogen was used as the reducing agent. Copper (I) oxide is supposed to show a smaller volume change upon reduction, but the reduction temperature $\left(572^{\circ} \mathrm{C}\right)$ was much higher than the temperature of the required bond formation process $\left(350^{\circ} \mathrm{C}\right.$ or lower). Currently, bond strengths of an interconnection formed using copper (II) oxide were about twice as low as those formed using silver (I) oxide. However, it may be possible to improve the bond strength by 
(a)

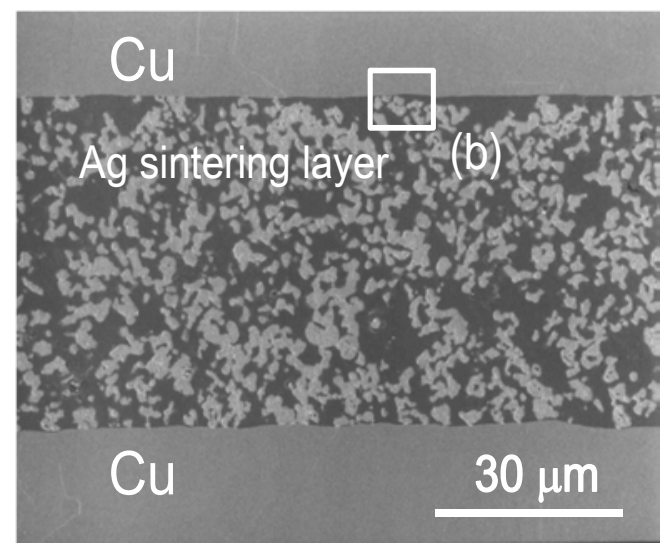

(b)

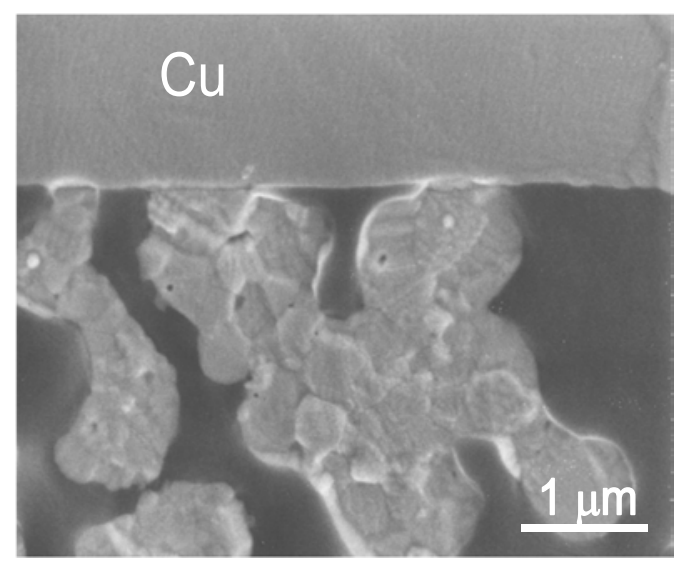

Fig. (9). Cross-sectional SEM imaged of silver (I) oxide. (a) lowmagnification image and (b) high magnification image of marked area in (a).

choosing different reducing agents. Therefore, copper (II) oxide is a good candidate material for future interconnections.

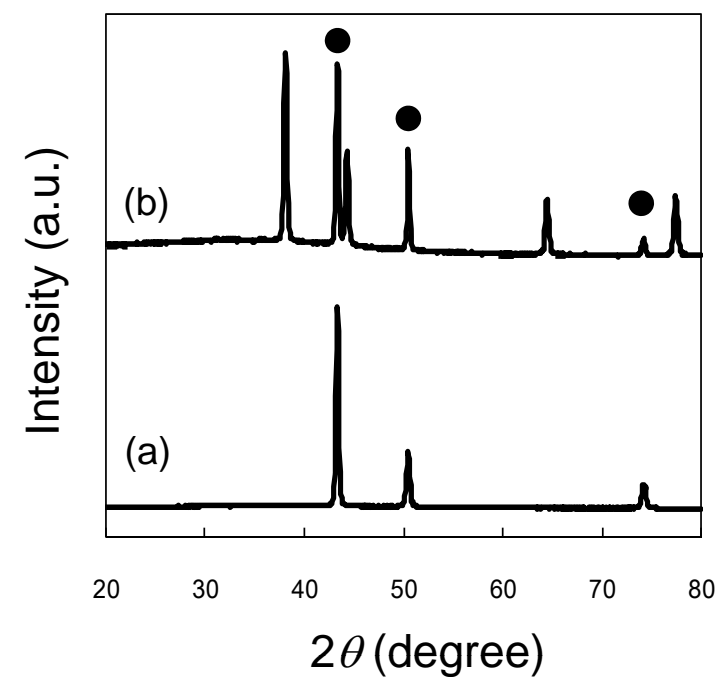

Fig. (10). XRD patterns of the fracture surface of the layer formed by using (a) copper (II) oxide and (b) silver (I) oxide for bonding at $350{ }^{\circ} \mathrm{C}$ (black circles are peaks attributed to copper disk).

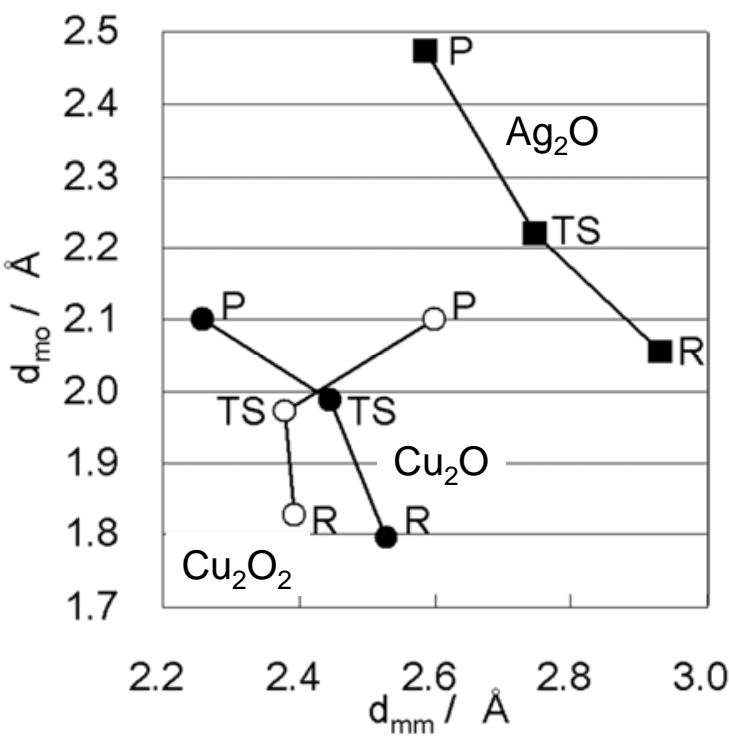

Fig. (11). Values of $d_{\mathrm{mm}}$ and $d_{\mathrm{mo}}$ of reactant (R), transition state (TS), and product (P) structures for the three metal oxide reduction reactions. See Fig. (4) for the definition of $d_{\mathrm{mm}}$ and $d_{\mathrm{mo}}$.

A combined analysis of theoretically calculated reaction paths for the reduction, measured TG-DTA curves, and shear test results revealed the following: calculated activation energies for the reduction reaction using a cluster model were highly correlated with the temperatures where the reduction started; higher stabilization energy upon reduction contributed to making the reduction time shorter via a chainreaction mechanism. This work is, as far as we know, the first case to apply ab initio quantum chemical calculations to analyze the reactions of interconnecting material. It was shown that theoretical calculation is a powerful tool to analyze and complement experimental data in this field.

\section{ACKNOWLEDGEMENT}

We thank Dr. Motoi Tobita (Advanced Research Laboratory, Hitachi Ltd.,) for valuable discussion about theoretical calculation.

\section{REFERENCES}

[1] Mahalingam M. Thermal management in semiconductor device packaging. Proc IEEE 1985; 73: 1396-404.

[2] Neudeck PG, Okojie RS, Chen L-U. High-temperature electronicsa role for wide bandgap semiconductors. Proc IEEE 2002; 90: 1065-76.

[3] Bai JG, Zhang ZZ, Calata JN, Lu G. Low-temperature sintered nanoscale silver as a novel semiconductor device-metallized substrate interconnect material. IEEE Trans Comp Package Technol 2006; 29: 589-93.

[4] Murray AJ, Jaroenapibal P, Koene B, Evoy D. Sintering of silver nanoparticles for the formation of high temperature interconnect joints. Mater Res Soc Symp Proc 2006; 942: 39-44.

[5] Morita T, Ide E, Yasuda Y, Hirose A, Kobayashi K. Study of bonding technology using silver nanoparticles. Jpn J Appl Phys 2008; 47: 6615-22.

[6] Lu G-Q, Calata JN, Lei G, Chen X. IEEE 8th Int Conf on thermal, mechanical and multiphysics simulation and experiments in microelectronics and micro-systems. EuroSime 2007; 609-13.

[7] Lide DR, Jr. Ed. CRC. Handbook of chemistry and physics $79^{\text {th }}$ ed Boca Raton, London, New York, Washington DC: CRC Press 1999. 
[8] Morita T, Yasuda Y, Ide E, Akada Y, Hirose A. Bonding technique using micro-scaled silver-oxide particles for in situ formation of silver nanoparticles. Mater Trans 2008; 50: 2875-80.

[9] Rodriguez JA, Kim JY, Hanson JC, Pérez M, Frenkel AI. Reduction of $\mathrm{CuO}$ in $\mathrm{H}_{2}$ : in situ time-resolved XRD studies. Catal Lett 2003; 85: 247-54.

[10] Kim JY, Rodriguez JA, Hanson JC, Frenkel AI, Lee PL. Reduction of $\mathrm{CuO}$ and $\mathrm{Cu}_{2} \mathrm{O}$ with $\mathrm{H}_{2}$ : h embedding and kinetic effects in the formation of suboxides. J Am Chem Soc 2003; 125: 10684-92.

[11] Pike J, Chan S-W, Zhang F, Wang Z, Hanson J. Formation of stable $\mathrm{Cu}_{2} \mathrm{O}$ from reduction of $\mathrm{CuO}$ nanoparticles. Appl Catal A 2006; 303: 273-7.

[12] Nakayama S, Kaji T, Shibata M, Notoya T, Osakai T. Which is easier to reduce, $\mathrm{Cu}_{2} \mathrm{O}$ or $\mathrm{CuO}$ ? J Electrochem Soc 2007; 154: C1C6.

[13] Peng C, Ayala PY, Schlegel HB, Frisch MJ. Using redundant internal coordinates to optimize equilibrium geometries and transition states. J Comp Chem 1996; 17: 49-56.

[14] Becke AD. Density-functional thermochemistry. III. The role of exact exchange. J Chem Phys 1993; 98: 5648-52.

[15] Perdew JP, Chevary JA, Vosko SH, et al. Atoms, molecules, solids, and surfaces: Applications of the generalized gradient approximation for exchange and correlation. Phys Rev 1992; B 46: 6671-87.
[16] Hay PJ, Wadt WR. Ab initio effective core potentials for molecular calculations. Potentials for the transition metal atoms Sc to $\mathrm{Hg}$. J Chem Phys 1985; 82: 270-83.

[17] Hehre WJ, Ditchfield R, Pople JA. Self-consistent molecular orbital methods. XII. further extensions of gaussian-type basis sets for use in molecular orbital studies of organic molecules. J Chem Phys 1972; 56: 2257-61.

[18] Legge FS, Nyberg GL, Peel JB. DFT calculations for $\mathrm{Cu}-, \mathrm{Ag}-$, and Au-containing molecules. J Phys Chem A 2001; 105: 7905-16.

[19] Frisch MJ, Trucks GW, Schlegel HB. Gaussian 03. 2004; Available from: http://www.gaussian.com/g_misc/g03/citation_g03.htm

[20] Araujo A, McNair JN. Individual- and population-level effects of antibiotics on the rotifers, Brachionus calyciflorus and B. plicatilis Hydrobiologia. Hague 2007; 593: 185-99.

[21] Reimer GJ, Gee SJ, Hammock BD. Comparison of a time-resolved fluorescence immunoassay and an enzyme-linked immunosorbent assay for the analysis of atrazine in water. J Agric Food Chem 1998; 46: 3353-8.

[22] Brown LM, Cowen RL, Debray C, et al. Reversing hypoxic cell chemoresistance in vitro using genetic and small molecule approaches targeting hypoxia inducible factor-1. Mol Pharmacol 2006; 69: 411-8

(C) Yasuda et al.; Licensee Bentham Open.

This is an open access article licensed under the terms of the Creative Commons Attribution Non-Commercial License (http://creativecommons.org/licenses/by-nc/ 3.0/) which permits unrestricted, non-commercial use, distribution and reproduction in any medium, provided the work is properly cited. 